\title{
MYOCARDIAL BRIDGING AND SUDDEN DEATH: A CARE REPORT
}

\author{
Juthika Debbarma1, Prasenjit Das², Antara Debbarma3 ${ }^{3}$, Pradipta Narayan Chakraborty ${ }^{4}$
}

\section{HOW TO CITE THIS ARTICLE:}

Juthika Debbarma, Prasenjit Das, Antara Debbarma, Pradipta Narayan Chakraborty. "Myocardial Bridging and Sudden Death: A Care Report". Journal of Evolution of Medical and Dental Sciences 2015; Vol. 4, Issue 01, January 01; Page: 116-119, DOI: 10.14260/jemds/2015/17

ABSTRACT: A 35 year old man was brought to casualty block of the hospital in the month of April by his family members with complaints of sudden unconsciousness. The doctors after examination pronounced him brought dead on arrival. Autopsy revealed myocardial bridging of the left anterior descending artery for a distance of $1.5 \mathrm{~cm}, 3 \mathrm{~cm}$ below its origin and the depth was $0.4 \mathrm{~cm}$. The left diagonal artery was located (LAD) into the myocardium for a distance of $1 \mathrm{~cm}$ and the depth was $0.3 \mathrm{~cm}$.About $30-40 \%$ narrowing of the left anterior descending artery is present due to atherosclerosis just below its origin. Histopathological Examination revealed no ischemic changes. Toxicological analysis report of the viscera confirmed absence of common poisons and ethyl alcohol. The cause of death was given as acute coronary insufficiency due to myocardial bridging.

KEYWORDS: Myocardial bridging, LAD, Sudden death.

INTRODUCTION: Myocardial bridge is a non-sclerotic anatomical anomaly of the coronary vessels leading to ischemic events. The coronary vessels run into the myocardial wall for variable length. ${ }^{1}$ The arterial segment within the myocardial wall undergoes compression during systole. Any compression over $70 \%$ causes myocardial ischemia leading to acute myocardial infarction. This anomaly was first reported by Reyman ${ }^{2}$ in 1737 at autopsy and was described angiographically by Portman and Iwig3 in 1960. The term "myocardial bridging" was proposed by Polacek ${ }^{4}$ in 1961. Geiringer in 1951 studied in depth the association of myocardial bridging with ischaemia. ${ }^{5}$ The presence of myocardial bridging is usually asymptomatic. Its presence is seldom diagnosed during routine angiogram in patients with chest pain and during autopsy. The frequency of such cases in coronary angiography varies from 1.5 to $16 \%{ }^{6}$ and in autopsy series it varies from 23 to $85 \% .^{7}$ The left anterior descending artery (LAD) is most frequently involved(60 to 70\%).7, 8

CASE REPORT: A 35 year old man was found muttering some incomprehensible words during his sleep by his wife at about 4:00am in the morning in the month of April. His family members tried to wake him up but he became unconscious. He was immediately shifted to hospital but he was declared brought dead at 4: $30 \mathrm{am}$.Autopsy was conducted on the same day at 12:10pm. There was no history of chest pain, heart disease and hypertension. No history of consumption of drugs or alcohol was given by the relatives. He was of average built. No external injuries were seen over the body. On examination of the heart, the dimensions were $14 \mathrm{~cm} \mathrm{X} 12 \mathrm{~cm} \mathrm{X} 5 \mathrm{~cm}$ and weight $400 \mathrm{gms}$.Multiple petechiae are present on the epicardial surface of the heart (Fig. 1). The left anterior descending artery was located into the myocardial wall for a distance of $1.5 \mathrm{~cm}$ and depth was $0.4 \mathrm{~cm}, 3 \mathrm{~cm}$ below its origin. The left diagonal artery was located into the myocardium for a distance of $1 \mathrm{~cm}$ and the depth was $0.3 \mathrm{~cm}$ (Fig. 2). The embedded segments revealed no atherosclerotic changes. The left anterior descending artery showed 30 to 40\%narrowing due to atherosclerosis, just below its origin. Rest of the arteries were patent. The valves of the heart were normal. Thickness of the left ventricular 
wall was $2.2 \mathrm{~cm}$ (left ventricular hypertrophy); right ventricle was $0.5 \mathrm{~cm}$ and of the atria was $0.2 \mathrm{~cm}$. The histopathogical examination revealed no ischemic changes. No contents were found inside the stomach and the mucosa was slightly congested. The toxicological analysis report of the viscera was negative for the presence of common organochloro, organophosphorus, carbamates group of pesticides, benzodiazepins and ethyl alcohol. The cause of death was given as acute coronary insufficiency due to myocardial bridging.

DISCUSSION: Myocardial bridging (MB) is a congenital anomaly where the coronary artery instead of lying in the epicardial fat it becomes embedded in the myocardium for variable length. Compression of such artery during systole rarely presents with any symptoms. However there are several cases reported which suggests association between sudden cardiac death and myocardial bridging 1 . Studies conducted have suggested possible relationship between cardiac arrhythmias and the myocardial bridging. ${ }^{9,10}$ The association between bridging and left ventricular hypertrophy have been reported, 7 11,12 and in the affected coronary artery generally no atherosclerotic changes are found at the bridging sites.The myocardial bridging predisposes the atherosclerosis in the proximal segment above the tunneling.4, 7,11-14 The left anterior descending artery is the most common artery involved and MB are most commonly embedded in the mid segment part whereas some authors have reported its occurrence in the proximal half of the artery.7,8,14 The longer intramural course of bridges and increase in intramural depth predisposes it to compression and hence ischemia during systole. The anomaly is therefore considered to be pathological when the tunnelled segment is $2-3 \mathrm{~cm}$ long and 0.2-0.3 cm deep. ${ }^{4,14}$ In the present case, myocardial bridging was found in the proximal half segment of left anterior descending artery and left diagonal artery with atherosclerotic narrowing in the proximal segment above the bridging and no atherosclerotic changes in the intramural part. There was associated left ventricular hypertrophy. All the findings in the present case are consistent with the literature in the previous studies conducted.

CONCLUSION: As the presence of myocardial bridging usually remains asymptomatic hence the prediction of morbidity or mortality due to this congenital anomaly is very difficult. At autopsy, in cases of sudden death due to suspected cardiac causes the presence of MB should be carefully explored especially in absence of any visible cardiac pathology.

\section{REFERENCES:}

1. Lilly LS, Braunwald E, Bonow R O. Braunwald's Heart Disease: A Textbook of Cardiovascular Medicine. Elsevier Saunders; 2012

2. Reyman HC. Disertatio de vasiscordispropriis. Med Diss Univ Gotingen, $7^{\text {th }}$ Sept. 1737; 1-32.

3. Portmann WC, Iwig J. Die intra murale koronar ieiman giogramm. Fortschr Rontgenstr 1960; 92: 129-132.

4. Polacek P. Relation of myocardial bridges and loops on the coronary arteries to coronary occlusions. Am Heart J 1961; 61: 44-52.

5. Geiringer E. The Mural coronary. Am Heart J. 1951; 41: 359-68.

6. Ge J, Erbel R, Rupprecht HJ, Koch L, Kearney P, Gorge G, Haude M, Meyer J. Comparison of intravascular ultrasound and angiography in the assessment of myocardial bridging. Circulation 1994; 89: 1725-32. 


\section{CASE REPORT}

7. Algeria JR, Hermann J, Holmes DR JR, Lerman A, Rihal CS. Myocardial bridging. Eur Heart J 2005; 26: 1159-68.

8. Mohlenkamp S, Hort W, Ge J, Erbel R. Update on myocardial bridging. Circulation 2002; 106: 2616-22.

9. Kracoff $\mathrm{OH}$, Ovsyshcher I, Gueron M. Malignant course of a benign anomaly: myocardial bridging. Chest. 1987; 92: 1113-5.

10. Endo M, Lee Y H, Hayashi H, Wada J. Angiographic evidence of myocardial squeezing accompanying tachyarrhythmia as a possible cause of myocardial infarction. Chest 1978; 73: 431-33.

11. Channer K S, Burkis E, Hartnell G, Rees JR. Myocardial bridging of the coronary arteries. Clin Radiol.1989; 40: 355-9.

12. Yetman AT, Mc Crindle BW, Mac Donald C, Freedom R M, Gow R. Myocardial bridging in children with hypertrophic cardiomyopathy - a risk factor for sudden death. N Engl J Med 1998; 339: 1201-9.

13. Edwards JC, Burnsides C, Swarm R. L, Lansing A I. Arteriosclerosis in the intramural and extramural portions of coronary arteries in the human heart. Circulation 1956; 13: 235-41.

14. Angelini P, Tinellato M, Donis J. Myocardial bridges: a review .Prog Cardiovas Dis.1983; 26: 7588.

15. Hill SF, Sheppard MN. Non-atherosclerotic coronary artery disease associated with sudden cardiac death. Heart 2010; 96: 1119-25.

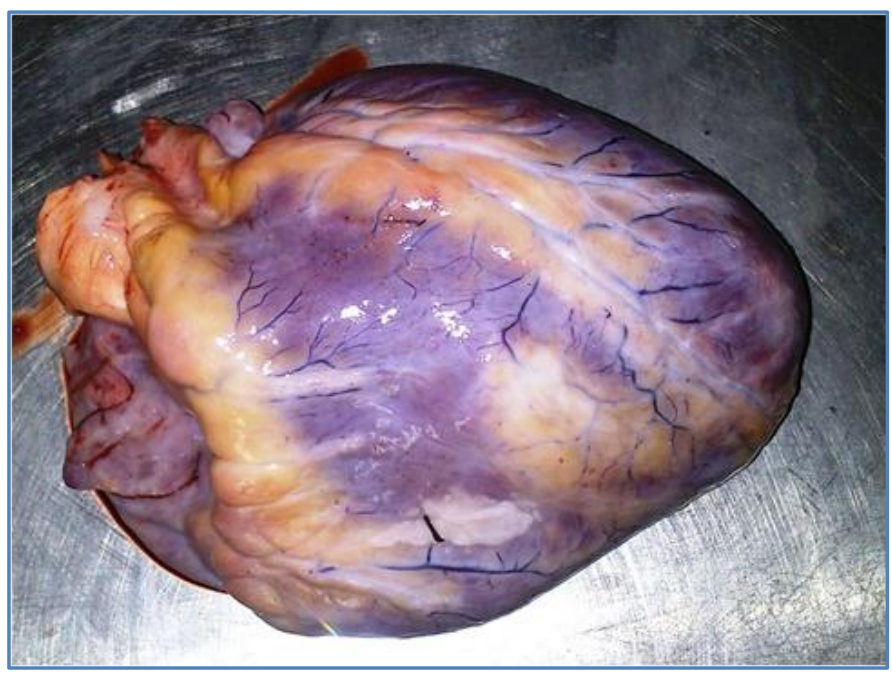

Fig. 1 : Multiple petechiae on the epicardial surface of the heart 


\section{CASE REPORT}

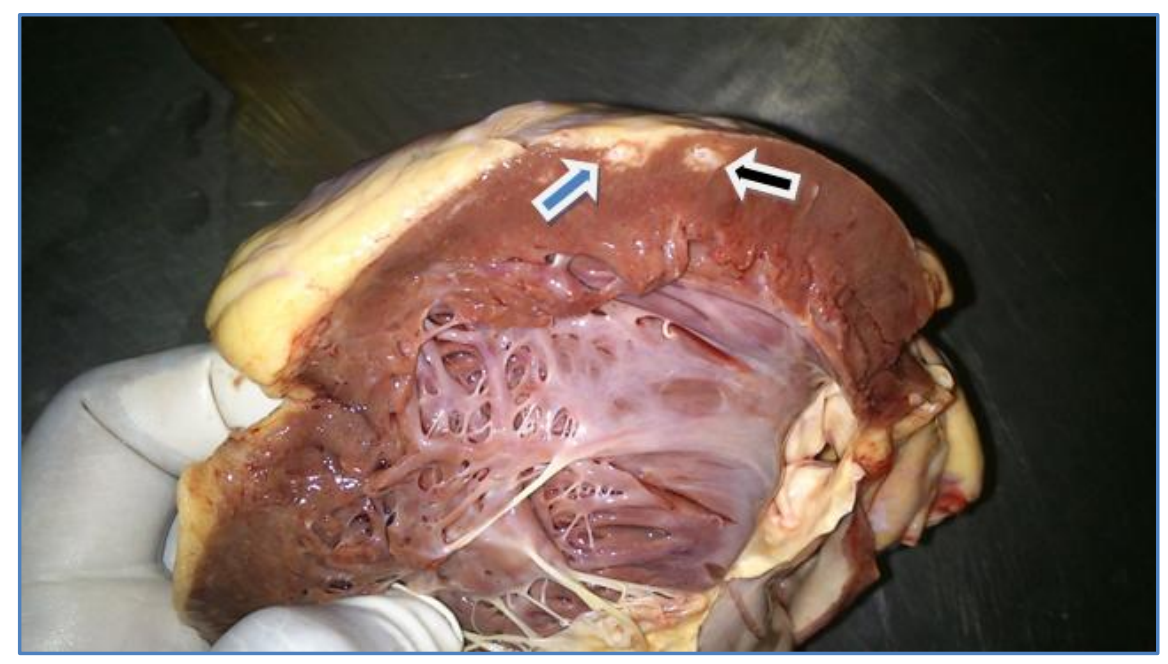

Fig. 2: Left anterior descending artery (Black arrow) and left diagonal artery (Blue arrow)

\section{AUTHORS:}

1. Juthika Debbarma

2. Prasenjit Das

3. Antara Debbarma

4. Pradipta Narayan Chakraborty

\section{PARTICULARS OF CONTRIBUTORS:}

1. Assistant Professor, Department of Forensic Medicine and Toxicology, Agartala Government Medical College and Gobind Ballab Pant Hospital.

2. Postgraduate Trainee, Department of Forensic Medicine and Toxicology, Agartala Government Medical College and Gobind Ballab Pant Hospital.

3. Postgraduate Trainee, Department of Forensic Medicine and Toxicology, Agartala Government Medical College and Gobind Ballab Pant Hospital.
4. Tutor, Postgraduate Trainee, Department of Forensic Medicine and Toxicology, Agartala Government Medical College and Gobind Ballab Pant Hospital.

\section{NAME ADDRESS EMAIL ID OF THE CORRESPONDING AUTHOR:}

Dr. Juthika Debbarma, Assistant Professor, Department of Forensic Medicine and Toxicology, Agartala Government Medical College and Gobind Ballab Pant Hospital, Agartala, Tripura (West), P. O. Kunjaban-799006.

E-mail: drjuthika.debbarma@gmail.com

Date of Submission: 15/12/2014.

Date of Peer Review: 16/12/2014.

Date of Acceptance: 22/12/2014.

Date of Publishing: 01/01/2015. 